\title{
Understanding Ethics-Quality Linkages In The Private And Public Sectors
}

\author{
John Mankelwicz, Troy University - Southeast Region, USA
}

\begin{abstract}
Customers ultimately define a product, while quality is best defined from the demand side. Thus, quality may be considered a weighted sum of quality attributes, $a_{i}$. This summation may be partitioned in various ways. The most plausible partitioning for both private industry and the public sectors involves a natural temporal and practical ordering for the components. Managers must consider the demands of many legitimate internal and external stakeholders, minimally satisfying all and further satisfying the most salient. There are linkages of particular $a_{i}$ to specific stakeholder groups. Technological standards and quality grading inform and regulate production by employees. Although quality maximization is often an excellent strategy, there is no universal, overarching ethical imperative to maximize overall quality. Rather, in the equations for both economic sectors, each component successively presents a distinctive set of demand related ethical issues.
\end{abstract}

Keywords: Quality, business ethics, management decisions, quantitative metrics

\section{INTRODUCTION}

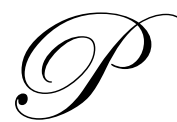

roduct and service quality continues to be an important topic in discussions of domestic and global business. The public generally assumes that more quality is always a good thing. Indeed, decisions on quality often take this tangent to the point that quality improvement takes on a moral imperative. However, in the short run, maximum quality may not be the profit maximizing solution for business, and it is by no means certain that the long-run situation is any different. Issues of quality can become very complex.

This popular and philosophical linkage of ethics, virtue, and the creation of quality has a long history (Gowdy, 2006). It appears to be even more prominent in Eastern philosophy, especially Zen. In Europe and the US, obsession with quality infused the Arts and crafts Movement. Recent popular literature has afforded quality a metaphysical significance (e.g., Pirsig, 1974). A full exposition of this trend is beyond the scope of this paper. Clearly, however, issues of quality intertwine with ethical issues, and there remain gaps in our thinking on these matters. This paper will seek to partially improve understanding by considering the ethics of consciously managing product or service quality in business enterprises. The discussion begins from a utilitarian position - particularly a social utilitarianism based on reducing uncertainties and transactions costs and establishing technological standards, thus clarifying expectations. It then expands into other perspectives. It is not strictly a Total Quality Management paper.

Central to discussion is the definition of the product or service; it is not what the seller sells, but rather what the customer buys. Buyers see the product as a bundle of attributes. The buyer weighs each attribute in importance in accordance with its perceived contribution to final utility. Hence, a weighted summation of attributes, $a_{i}$, is the quality of the product. Some quality attributes merely involve complementarity; i.e. complementary use with another good or service. This downstream aspect of quality is generally neglected in the literature, but it will be a prime focus in this paper. 


\section{QUALITY}

Every aspect of corporate activity somehow involves issues of quality, although most discussions focus on the central segments of a company's value chain and the activities of its productive core. Inputs must be of adequate quality; the quality of productive processes is checked; outputs are monitored using various quality control techniques. At some point the inputs from marketing and sales feedback must be integrated into production, since it is customers who ultimately define the product or service.

\section{Buyers' Quality}

Buyers may be concerned with a single attribute of a good or service, or they may be concerned with many. Not everyone will desire the same attribute(s). Indeed, a good or service may be considered as a bundle of attributes sold together. Entrepreneurs market new goods with a distinctive mix of these attributes. The total perceived quality of a good may be defined as

\section{Eq. (1) Quality $=\sum_{i=1}^{n} \alpha_{i} w_{i}$}

where, $\boldsymbol{\alpha}_{\mathbf{I}}$ are quality attributes, and $\mathbf{w}_{\mathbf{i}}$ are the weights that buyers give to each attribute

The use of key attributes, rather than mere physical description, in hedonic regression and related methods to define a product is long established in economic practice. It is the standard tool to track both the overall quality improvements and possible inflation, through the real Consumer Price Index, particularly in housing components (Rosen, 1974; Liegey, 2000; Triplett, 2006). In this framework it is clear that buyers, not producers, define quality. Quality is thus properly understood as primarily a demand side concept.

\section{Producers' Quality}

Most discussions of quality, including those relating to Total Quality Management, emphasize the supply side. A wide array of quantitative methods is available, including the well-known operations management tools such as process control or statistical quality control. Proceeding through the big strategic decisions into day-to-day operations, decisions become less ambiguous at each sequential stage. They usually become more programmed and more dependent upon specific indices or organizational rules. Reliance on ISO 9000 standards and other authoritative material clarifies the task, creating (and hopefully justifying) expectations of quality output. Utilization of these methodologies has great consequence. Quantitative methods are part of managers' efforts to be "intendedly rational;" yet they achieve only a "bounded rationality" (Simon, 1945). They seek and use data to make decisions, to ratify them, and to "sell" or defend them. At their most useful, quantitative models and their numerical outputs accurately describe an actual state of affairs or provide the best projection of one. The precision in magnitude, location, and time description of variables is the key to problem formulation (Kepner \& Tregoe, 1965), the foundation of effective decisions. Numbers can also represent theoretical equilibria, optima, or desired states.

It is essential to consider the human side of quality management as well. Executives' intelligence, creativity, personality, values, specific abilities, insights, and even social outlook can and do impact formulation of the firm's mission, vision and objectives (Andrews, 1971). These strategic choices thus reflect and reveal the corporate attitude toward quality. The commitment to quality may be minimal or intense. The commitment may be expressed through different emphases. Presumably, management teams dominated by individuals with operations and technical backgrounds will focus on quality in production, while marketing dominated teams would emphasize creating and meeting buyers' preferences of quality attributes.

Fundamentally, private enterprise differs from public administration in that there is the single, clear objective function for private sector managerial decisions: maximization of shareholder wealth, effected through highest stock price. This mandate is inherent in corporate law, which defines directors and executives as agents of the stockholders. Even if stock is not publicly traded, the owner(s) is ordinarily concerned with the eventual sale value of the enterprise. However, the markets do not reward unprofitable organization growth, in either the long or short runs (Hax \& Majluf, 1984). Hence, executives concentrate on maximizing profit, which may be considered as 
revenue minus expenses. The focus is typically short run, usually quarterly. Although expectations and discount schemes may vary, the stock price is thus theoretically the present value of the discounted stream of payments (dividends) to the stockholder.

Investments to improve the quality of both processes and final products may be a key method of expanding market share, as well as corporate reputation and profitability. Improved profits provide organizational slack, some of which can be redirected into further quality enhancements. Figure 1 below depicts this process graphically. Successful quality improvement is shown as a virtuous, not vicious, cycle. This especially allows firms with clearly differentiated products, which most quality concerned firms probably are, to sustain the competitive advantage in this manner. Actually, all of Porter's (1980) generic strategies can benefit from quality. It may be that even a cost leader, stressing high sales volume and low price, must first demonstrate to the market that its quality levels are adequate and consistent.

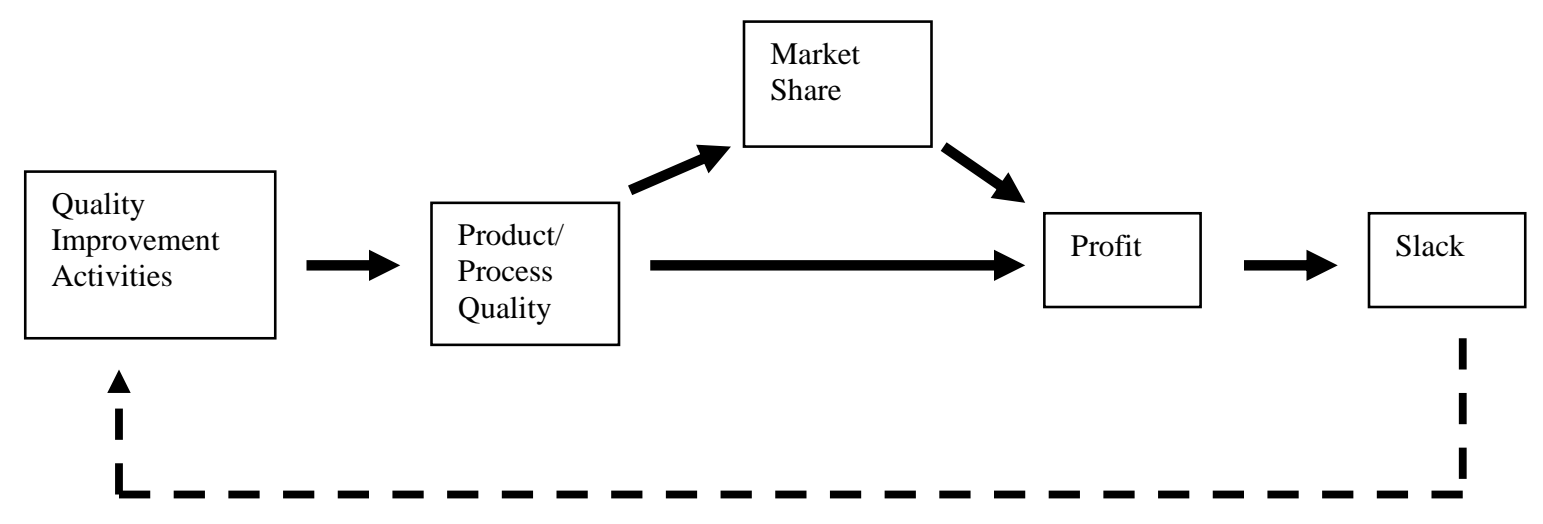

Figure 1: Quality improvement activities improve market performance.

\section{ETHICS AND QUALITY}

Quality begins as an utilitarian/economic topic. Its relation to ethics is thus first considered in terms of utilitarian ethics. Also, because of the high organizational culture commitment required for sustainable and continuous quality improvement, the organizational ethic - what otherwise acceptable things that are good for the organization - takes special place as well. While all schools of thought and ethical principles may be applicable, these two views underlie this discussion.

\section{Ethics}

Ethical standards and norms of behavior became necessary early in human history as the free actions of individuals began to hurt others. When norms and taboos failed to control harmful behaviors, people entered into some form of social contracts that typically gave power to a sovereign in return for protection, and, in a larger sense, some degree of enforcement of what "should" be. Most ethical beliefs arise from religions and are reinforced in family practices, which of course involve consumption, sharing, and cleanliness. Shared ethical beliefs are a cardinal element of culture. Today, governments will not ordinarily encode these beliefs and values into law unless there is substantial social agreement that the consequences of nonconformance are clearly hurtful. While some ethical norms may be nearly universal, there is still considerable difference in attitudes and practices not only across but also within societies and nations.

Human values are a driver of one's personal sense of obligations and loyalties. These two concepts - values and obligations - along with posited relationships between them, are the core of ethics. From ethics in turn, humanity draws its sense of what should be. Matters of value and obligation are hard to quantify. The lack of universal consensus on ethics further compounds this difficulty. Even within a purely utilitarian ethical framework, treating 
values and obligations as economic utilities, the results may be no more than nominal or ordinal level "numbers." Beyond this, some assert that the real constituents of human thought are not numbers or quantities at all, but the "labels of fuzzy sets" (Zadeh, 1965). To Zadeh, these labels distinguish human intelligence from that of the machines. Perhaps the best recent attempt at ethical quantification is Jones' (1991) concept of "moral intensity," which can serve as a crude surrogate of both the degree to which values are generally violated in a situation as well as the sense obligation on a focal actor to deliberate or act. However, Jones' overall model deals with issues and outcomes, and does not prescribe specific values or ethical principles.

Ethical problems are in some sense similar to practical ones, as individuals become aware of a moral gap between actual behaviors and those presumed under an accepted code. Problems may be considered as "gaps" between a desired state of affairs and an actual state of affairs (Kepner and Tregoe, 1965). In practical problems, professionals and managers rely largely on the most established theories and practices of their functional areas to know which specific variables to consider, observe and measure. Which constants to assign, which parameters to estimate? Once learned and accepted, these "paradigms" (Kuhn, 1980) work within the organizational context to give organization members mental schema to guide thought and action. Practitioners can refer to representative works as the "exemplars" of the underlying paradigm (Kuhn, 1980). Thus paradigm and theory inform the search for information, giving meaning to the raw data and events in terms of time, setting and people; they allow the data to become true information. By suggesting relevant variables and methodologies, paradigms treat problems as solvable "puzzles", with definite solutions (Kuhn, 1980). By comparison, the desired state in a moral problem is some standard of conduct or value adherence. Figure 2 depicts the nature of an ethical problem gap.

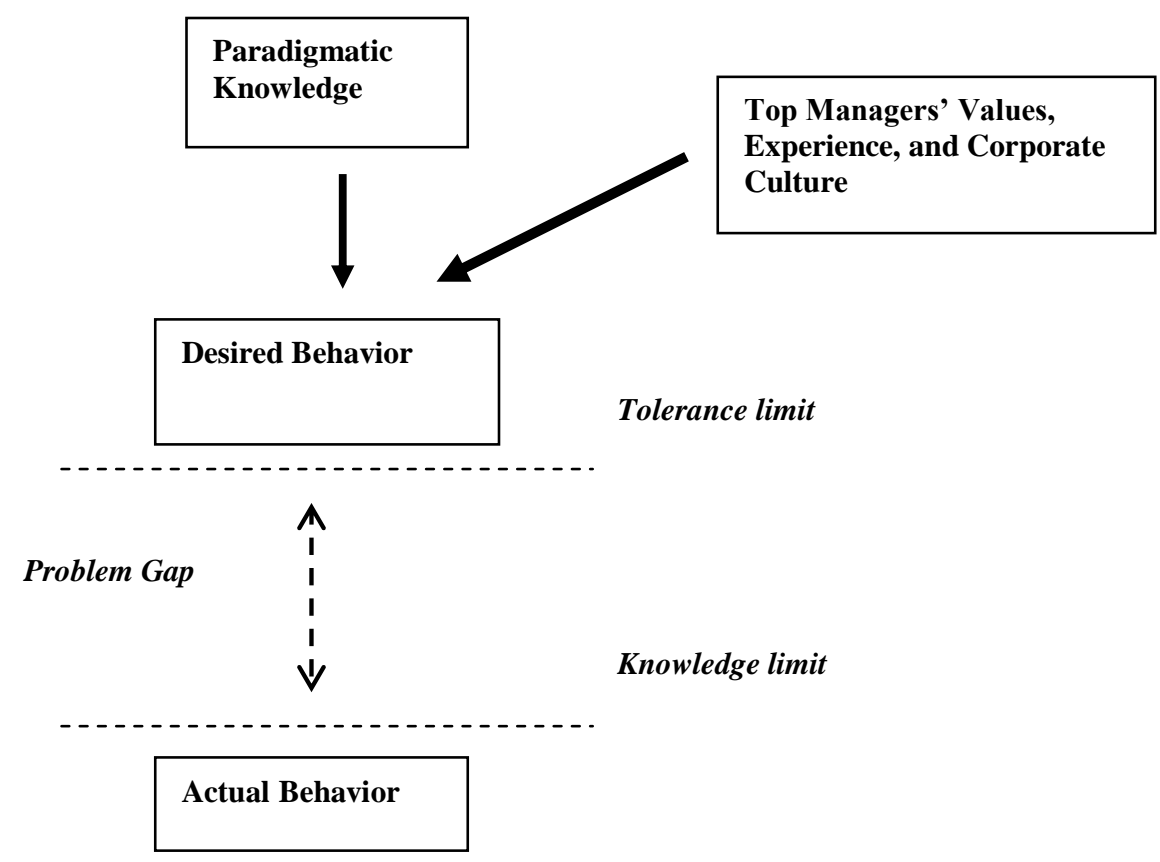

Figure 2: Ethical problems are analogous in structure to practical problems.

Experience and organizational context may suggest reasonable tolerance limits for deviations from the ideal levels; tolerance limits determine which problems managers recognize and accept. Paradigms also guide management in how to observe or measure the actual levels. Similarly, there is a limit to just how closely the actual current state of the variable can be known - the knowledge limit. The parallel in ethical problems is strong. Accepted mindsets and practical knowledge of the industry become the "paradigm," suggesting reasonable and hence desired standards of conduct. Managers' own values and experience also influence choice of a desired state, as do the ethical premises in the particular corporate culture. This applies also to attitudes toward quality. Some craftsman like top 
management teams would strongly identify themselves and their companies with high product quality; they have the mandate to do so (Andrews, 1971). In these firms, the issues of product quality take on pronounced ethical and cultural tones. However, there is no clear ethical imperative for a business firm to maximize quality, as defined above, although it may be profit-maximizing solution in the short or long runs.

From ancient times there has been some friction between the private and public perspectives concerning ethics. Merchants and others who performed the distribution and sales functions of early commerce sought to police themselves through common understandings, agreed quality standards, and rules enforced by the owner-managers of local fairs. These simple arrangements served to guide ethical dealings between merchants while preserving principles of commercial feasibility. They provided some protection to buyers even in a caveat emptor world. Perhaps most importantly, they partially isolated merchants from agents of the sovereign or the local authorities. The view was that such officers would know nothing of commerce or technology, swing swords well, and have their hands out for favors. These early guidelines were later formally recorded in the English Lex Mercatoria. They form the basis for the modern day US Uniform Commercial Code.

The guiding paradigms for most practical problems emerge from a positivist research tradition with emphasis on description, measurement and quantification. Consider finance, marketing, operations etc. All of these functional areas rely on disciplines with accepted paradigms that suggest (even prescribe) the sets of concepts, variables, and methods proper for use in analyses. By contrast, the "paradigms" of business ethics have evolved slowly over a long historical period, and are strongly influenced by the Judaeo-Christian ethic and tradition, at least in the western world.

\section{Moral Intensity}

Ethical problems are not without degrees of comparison, but they are not truly quantitative. A very important attempt at ethical quantification is Jones' (1991) model, which introduced "moral intensity." This concept can serve as a crude surrogate of both the degree to which values are generally violated in a situation as well as the sense of obligation on a focal actor to deliberate or act. However, this model deals with issues and outcomes, and does not prescribe specific values or ethical principles. Having recognized an ethical problem, managers then pass through the stages of moral judgment, intentions to act, and finally actions (Rest, 1986). The greater the moral intensity (Jones, 1991) of an issue or problem, the more likely an individual will continue through the steps of this process, proceeding toward actual, intentional moral behaviors. The moral intensity concept encompasses six measurable dimensions: magnitude of effect, probability of effect, concentration of effect on a specific group(s), social consensus on the issues, immediacy in time, and proximity in space. However, it is obvious that the quantification of ethical matters is still relatively new and naïve.

Empirically, the magnitude of effect and a general social consensus greatly facilitate initial moral awareness in competitive business environments when the discussion contains explicit moral language (Butterfield, et. al., 2000). Indeed, many aspects of organizational context may act to facilitate or impede intention ever becoming behaviors (Jones, 1991), good or bad. Individuals' differences also interact with the characteristics of the issue, as defined by moral intensity (Trevino, et. al. 2006); in particular, "Utilitarians" become aware of fewer moral issues than "Formalists" (Reynolds, 2006). There is a further ironic twist to this discussion. Everyone seems to attach moral significance to unjustified and clear-cut instances of physical or financial harm. Yet Reynold's (2006) utilitarians, presumably more quantitatively oriented, seem to have less moral awareness, especially in issues that violated social norms. It may be that, at least in the short run, a person's reliance on numbers oriented paradigms may actually hamper the ethical sphere of decision. For instance, partners in CPA firms generally showed lower moral reasoning than lower level employees (Ponemon, 1992); accountants and accounting students similarly scored lower than comparison groups from other fields (Lampe \& Finn, 1992). Stock price, reported profit, ROA, risk adjusted measures, quick ratio, market share and other indices are the bases for many decisions. Ironically, corporate miscreants must initially appeal to the very respect accorded these measures to perform a successful distortion of fact. The distortion itself is possible usually through over aggregation of data or the unrecognized lack of correspondence between the actual aspect of the situation (concept or construct) and the accepted measure (Boyd, et. al., 1993). However, it is finally the very quality of the procedures and measures that insures such fraudulent success is temporary. 


\section{PRIVATE ENTERPRISE}

Like any other efforts at description, comparisons and contrasts between public administration and private management may take divergent paths and result in different statements. For the purposes of this paper, the fundamental distinction between the two endeavors is that there is the single, clear objective function for private sector managerial decisions: maximization of shareholder wealth, effected through highest stock price. Even if stock is not publicly traded, the owner(s) is ordinarily concerned with the eventual sale value of the enterprise. However, the markets do not reward unprofitable organization growth, in either the long or short runs (Hax \& Majluf, 1984). Hence, executives concentrate on maximizing profit, which may be considered as revenue minus expenses. The focus is typically short run, usually quarterly. Although expectations and discount schemes may vary, the stock price is thus theoretically the present value of the discounted stream of payments (dividends) to the stockholder. The 'public' sector may be considered to consist not only of government, but also the many associated non-profit organizations that serve the public interest (Frederickson, 1997). These entities do not publicly sell stock, and many do not seem to clearly and persistently pursue maximization of net revenue. There does not appear to be one characteristic and overriding objective function for the public sector, and it is not clear that all public bodies even have an objective function. Public sector decision-making may be largely informed by incrementalism (Lindblom, 1959), in which actions are considered beneficial if they perceptively improve the situation in regard to some relevant variable(s).

These fundamental differences have significant implications, especially for the manners in which the process of quantification proceeds in the private and public sectors. It is possible to describe quantification in theoretical terms or by abstract qualities of the resulting information and metrics (e.g., timeliness, simplicity, etc.). However, this discussion will focus on what administrators do and the methods and tools they use. The implications touch such areas as quality, impact of cyclical factors, the nature of unlearning, learning and change, and ethical issues.

\section{Profit Function}

While profit may be considered as simply total revenue minus total cost, the objective function for profit should be given as the skeleton form of the constrained equation,

\section{Eq. (2) Profit $=$ Revenue - Costs $-\sum_{\mathrm{i}=1}^{\mathrm{n}} \lambda_{\mathrm{i}} \mathbf{f}\left(\mathbf{X}_{\mathrm{i}}\right)$}

where each lambda term is a Lagrangian constraint. It may be expanded easily with econometric or duPont analysis, yielding larger equations that are tractable but tedious. The $\mathbf{X}_{\mathbf{i}}$ may in principle refer to almost any variable that would be a component of the revenue or cost terms.

Most constraints will be limits imposed by legal mandates, such as minimum wage considerations, safety concerns, or environmental protection. Some may be self imposed, resulting from interactions with external stakeholder groups, requests from shareholders, or management's own sense of social accountability. (There is of course the rare special case with no Lagrangian constraints at all.) This social position may also include constraints to ensure high quality products. In addition to ethical purposes, the "constraint" of a quality emphasis may be a powerful competitive weapon if it signals quality to the customer, gaining his trust and confidence. Indeed, high quality may be considered as an intermediate goal on the route to profit. The company makes essential choices in this vein: optimizing a short term quality level to maximize short term profits, or striving for continuous improvement to become a quality leader, build reputation, and maximize the long term profit stream. It may take relatively simple measures such as using only inputs with strong ISO 9000 and adhering carefully those standards itself, or it might undertake more ambitious and comprehensive measures.

The four major terms of the equation each suggest a category of intervention points for managerial action to increase profits. Action at each point has its unique character and outcomes. Management emphasis, and concern for precise quantification, will shift from term to term as conditions change. Consider each of the four terms in turn. 
Profit

This is the area where business executives have the least discretion. Their direct, substantive profit impacts are virtually all attained by manipulating the three terms on the right of the equation. Measures aimed toward profit itself are primarily acts of timing and signaling undertaken to change or maintain expectations and thus influence stock price. They usually concern announcements about such issues as anticipated revenue and profit, new products, joint ventures, changes in the top management team, etc.

\section{Revenue}

Executives have some discretion in this area, if customers cooperate.

Costs

This is the area of greatest managerial discretion. It involves a galaxy of measures ranging from simple efficiency improvements to retrenchment in entire markets and sale or dismantling of entire corporate divisions. Such measures may involve steep current charges, but the financial community may perceive them as contributing to long-run health of the enterprise. Some costs may be deferred, with apparent temporary incremental increase to profit.

\section{Constraints}

Managers have modest discretion here. Since constraints are not usually directly stated in monetary terms, the firm may learn to fulfill the constraint with less cost. Companies may lobby to remove regulatory restrictions, negotiate with various stakeholders. They may rely on joint ventures, strategic alliances, networks, board interlocks, or trade associations.

\section{Partitioning Quality}

The quality attributes, $a_{i}$, of an end product differ not only in their weighing by the consumer, but also in their fundamental nature and when they emerge from the sequential productive activities of the firm's value chain. Some $\mathrm{a}_{\mathrm{i}}$ are essential, attributes of a product, even if it is a commodity. While commodities are generally defined by a contract, not by physical attributes, it is intuitive that a commodity may be a good to some buyers elsewhere. Some buyers of commodities may immediately seek to resell them as goods. Thus it is appropriate to consider a core set of attributes. Usually, however, a reseller will add some attributes, even if only in packaging, location, available service, prestige symbols, etc. In the case of a clearly differentiated product, there would be some second set of perceived "brand" attributes, carefully directed toward the most salient customer stakeholders (Mitchell, et. al., 1997). A product may contain still other attributes that customers desire. Jobbers or retailers may create this peripheral set, e.g., dealer preparation of new automobiles. It is actually possible that some attributes in any of these sets may be produced unwittingly or serendipitously, and still be desired by the consumer. Consumers themselves may create a final set of $a_{i}$ through the process of household production, e.g., striping a new car. Hence, for the purposes of analysis and discussion, equation 3 provides a partitioning of the overall set of quality attributes. Interestingly, the firm itself, the retailers, or even householders may produce the particular $a_{i}$ that are complementarities to other products.

Eq. (3) Quality $=\underset{\text { Core set }}{\sum_{i=1}^{n} \alpha_{i} w_{i}}+\underset{\text { Brand set }}{\sum_{i=1}^{n} \alpha_{j} w_{j}}+\underset{\text { Retail set }}{\sum_{i=1}^{n} \alpha_{k} w_{k}}+\underset{\text { Household set }}{\sum_{i=1}^{n} \alpha_{1} w_{1}}$

Intuitively, firms produce these four component sets of $a_{i}$ sequentially, from left to right. Producers apply most quantitative techniques, including efforts at Total Quality Management, toward the core set, and possibly the brand set also. This is similarly the case for the human factors of trust, empowerment, and culture building believed to be at the heart of continuous quality improvement. It is certainly possible for a single firm to produce not only the core and brand, but the retail set also. However, the production of each attribute set may require considerable and perhaps rare skills. Also, the mindset of a firm's owners, top managers and other members of the organizational 
coalition may lean heavily toward only one of the sets. When a firm heavily leans toward one of the sets, the concomitant skills and orientation inform the dominant logic (Prahalad \& Bettis, 1986) of that organization. However, rapid technological change and market turbulence present perils to jobbers or retailers who add $a_{i}$ that enable use of a product with its complementary goods. Similarly, the complementor "niche" producers themselves are especially vulnerable to market and financial loss (Pierce, 2009).

Market transactions are strategic interactions, and are by nature situations in which an actor's final outcomes are determined not only by what they do but also by what other actors do (Morgenstern \& von Neumann, 1947; Nash, 1951). The complexity is greater yet because the exchange of signals - about price, quality, availability, etc - is occurring not across dyadic linkages, but really across a vast network of present and potential stakeholders. Further, buyers and sellers must be alert to two kinds of signals: those intentionally generated and transmitted by another actor(s), and those that are not intentional. Managers often intentionally release data to signal a decision, or to affect a feint or bluff; numbers are essentially symbols, and often powerful ones. Release and skill presentation of information is a key factor in successful advertising, improving customers' overall valuation of a product or service or prompting them to raise the weighting of a specific quality attribute(s). Data can actually take on a significance that is somewhat independent of their specific values, or their accuracy. Decision makers, including consumers, are prone to attribute greater credibility and importance to numerical data obtained very recently (Boyd, et. al., 1993) or very early in their search activities (Kozielecki, 1972).

\section{Quality and Life Cycle}

There are many macro environmental factors (e.g., the business cycle, the emergence of major new technologies) that could impose exogenous shocks, altering the composition within sets of the model described above. These shocks can also decrease (possibly increase) the resources available for informational search. Contemporaneous appearance of signals from many sources burdens the information and attention capacities of an organization. If the firm or agency already has serious problems, it is likely impaired in the abilities to acquire information and amplify signals. The size and age of organizations might also be strong contingency factors in their information processing.

A full treatment of all contingencies is well beyond the scope of this paper. Discussion will therefore focus on the phenomenon of markets and industry life cycles. Early in a cycle, there is strong demand for new features and quality attributes. Indeed, a good or service may be considered as a bundle of attributes sold together. Entrepreneurs market new goods with a distinctive mix of these attributes. In this framework it is clear that buyers, not producers, define quality. Quality is properly understood as a demand side concept. Producers and sellers may, however, succeed in persuading buyers to more heavily weight certain quality attributes. This is a prime function of advertising. While the market demands new attributes and / or expanding production, the emphasis of quantification will be on the revenue term in the overall profit function. It is also possible that businesses will, for a variety of reasons, add constraints that fix quality above a certain level.

Markets mature. As they do, buyers may diverge into market segments. However, over time, buyer experiences allow convergent expectations of usefulness. Demand shifts toward relatively standard attribute mixes sold at a lower price. Commoditization is at work. Inefficient firms fail or leave the market. For remaining suppliers, innovations are aimed at cost control in production and distribution. Of course, it is possible for technological or societal developments to alter and revive industries, thus renewing the cycle.

\section{Ethical Quality Issues}

Most ethical discussions arise from the myriad of issues stemming from producer choices. These issues concern both top managers and any brand manager. Again, there is no moral imperative to maximize the total quality of a product. The imperatives for business are maximum shareholder value and profit. These may not occur at maximum quality level unless buyers demonstrate a clear willingness to buy it. However, quality maximization is often a very good strategy. Every management should at least consider it, at least in the stages when corporate and brand images are forming. 
There is a very clear imperative, however, to avoid all fraud and deception in representations of the firm's quality levels in its products and services. It is also desirable that a corporation publicly indicates its posture toward quality in its mission, vision, values, and ethics statements - with consistent, commensurate conduct in follow-up. Building a culture of continuous improvement is probably the most important element in this conduct. There must be especially rigorous attention to quality related contractual commitments, both to customers and from the firm's own suppliers. If quality is an announced focal issue, then top managers must verbally and physically demonstrate their commitment to it.

All of this will involve intense mindfulness as well as publicly visible action. With or without a formal TQM program, managers must promote work force concern toward quality issues, with attendant empowerment to act in the relevant Mindfulness must extend externally as well toward long-run effects on the firm's markets, emerging technologies and industry standards, the opportunity costs of quality commitments, and possible externalities, such as pollution.

\section{Ethics and Quality Failures}

Top managers run large and diversified organizations on the basis of reported numbers for the ostensible purpose of maximizing stockholders wealth. Engineering, finance, accounting, and industrial economics all stress the quantitative. The whole field of Quality Control focuses on consistent gathering and analysis of real data.

Why then are there so many boondoggles and oversights? The fault is not with the data, nor even with the processes for quantifying quality. The biggest factor is people

Stockholders, the financial press, and the board - that can directly ratify the CEO's rewards or administer her/his dismissal - define the performance of the CEO by the performance of the organization. Again, at this level, performances are largely defined by formal, quantitative, and especially financial criteria. Given the magnitude of the loss possible from poor strategic decisions, ethic laxness, or quality failures, it becomes important to know what CEO's and other top managers actually do recognize as important. Following the methodology of Herold and Greller (1977), Mankelwicz, et. al. (1987) studied the feedback information that CEO's actually use in a very quality intensive industry - financial services. These executives focused on positive feedback related to the quality of their services - first from "objective" numerical data, and then from "softer" social sources. More masculine CEO's especially tended to downplay negative feedback, whether objective or social. The CEO's were thus truly attentive to the numerically based measures used by outside stakeholders, while remaining oriented more toward opportunity grasping rather than problem seeking and solving. Attribution theory provides further insight. Based on the seminal work of Heider (1944) and Kelley (1967), attribution theory suggests that individuals reason backwards from the knowledge of results of past episodes, through actions and processes, to make attributions about the character, ability, and motives of other people, as well as the quality of things. Behaviors and outcomes that are unexpected and chosen freely are considered especially revealing of these things (Jones \& Davis, 1965).

Contextual and structural factors can aggravate human frailty. Monetization allows numerical comparisons across an organization, industry, or economy. Yet conversion to monetary units distorts some quantities, while other variables are notoriously difficult to quantify (e.g., the value of your life). Further distortion is produced by the very size and nature of modern organization with its hierarchically upward flow of reported numbers (aggregated at each level) and downward flow of instructions and authorizations. Aggregation makes it easy to hide errors and quality failures; even more fundamental, it renders the information less specific and less timely. It is less useful for either learning or unlearning. Hence, top managers often respond on the basis poor quality information. If the findings of Reynolds (2006), Trevino, et. al. (2006) and others can be generalized, then those at the top are both hampered in detecting practical problems and personally less aware of ethical ones. Even with rather good intentions, managers may begin "problemistic search" (March \& Simon, 1958) rather late. Thus it may be true that, at least in the short run, reliance on numbers oriented paradigms may actually hamper the ethical sphere of decision.

\section{PUBLIC SECTOR}

As one prominent author so eloquently stated, "values are the soul of public administration," (Frederickson, 1997: 160). Values to some degree drive the human sense of obligations and loyalties. These two concepts - values 
and obligations - along with posited relationships between them, are the core of ethics. It is from ethics in turn that humanity draws its sense, not necessarily of what actually is, but of what should be.

It has been suggested that the bane of public administration is that it must rely on crisp procedures to fulfill "fuzzy mandates" (Lerner \& Wanat, 1983). Without the guidance of an overriding objective function, the purposes and mandates of public administrators must seem fuzzy indeed when compared to the shareholder wealth and profit focus of private sector management. In this milieu an incrementalist mode of decision-making may be not only descriptive of most public administration, but appropriate as well. Applying crisp measures, managers "satisfice" (Simon, 1945) the demands of salient stakeholder groups.

\section{Public Administration Quality}

The public are consumers of the quality attributes of public services. As for private industry, the total quality of services is a weighted sum of quality attributes. As a starting point, analysis may usefully partition these attributes by the generally accepted priority of attention given to public responsibilities. Hence.

Eq. (3) Quality $=\sum_{i=1}^{n} \alpha 1_{i} w_{i}+\sum_{i=1}^{n} \alpha 2_{j} w_{j}+\sum_{i=1}^{n} \alpha 3_{k} w_{k}$

where,

$\boldsymbol{\alpha} \mathbf{1}_{\mathbf{i}} \quad$ are public safety-related attributes

$\boldsymbol{\alpha} \boldsymbol{2}_{\mathrm{j}} \quad$ are infrastructure related attributes, and

$\alpha \mathbf{3}_{\mathrm{k}} \quad$ are public amenity related attributes

There is no necessary temporal sequence in which these attributes are produced, and the same public servants may be involved in production of more than one set, e.g., maintenance crew working on both highways (infrastructure) and parks (amenities). While the priority is in the attention given by key decision makers, it ordinarily is also reflected in budgetary arrangements. It is not necessary for the weights to sum to unity; analysts may use any consistent weighting scheme. For convenience, let each $\boldsymbol{\alpha}_{\mathrm{i}}$ take a range from zero to unity.

Then some $\alpha_{i}$, particularly those in the public safety and infrastructure sets, will have values of 1.0, because they are mandated by law. The values of other $\alpha_{i}$ may approximate 1.0 because of high demand by the public. Some amenity set $\boldsymbol{\alpha}_{\mathrm{i}}$, and some $\boldsymbol{\alpha}_{\mathrm{i}}$ from the infrastructure set also, may have very low values. These might be considered "superior public goods," for which the demand is high only in times of high disposable income or abundant tax revenue. The actual weightings will vary by jurisdiction and over time.

\section{Societal Cycles}

In meeting these demands, administrators face an apparent parallel to market life cycles. Many theorists believe public administration in America, and possibly over the western world, follows general societal cycles: periods in which the chief demands on administrators are for "responsiveness" alternate with periods of demand for efficiency and accountability (Hirschman, 1982; Kaufman, 1985; Frederickson, 1997). The nature and purpose of quantification will differ substantially depending on the stage of this cycle.

Although there is no single overriding objective function like profit, it is still possible to define in principle what rational administration implies for each stage. Consider first the measures. When the zeitgeist is for efficiency, there should be a clear emphasis on accepted measures, drawn from accounting principles and the standard technical practice. New measures may be forged, especially to monitor the performance of internal stakeholders that perform the operating functions. Measurement of course means measurement of the indicants of properties of things, real or 
abstract. In principle, the expectation is that measurement during such periods concentrates on the more volatile "state like" properties, and their relationship to monetized variables.

When the call is for responsiveness, there should be efforts to tailor measures that appeal to specific stakeholders - especially stakeholders external to the organization. Every common measure has its constituency; otherwise it would not be in common use. Presumably there would be some effort to measure and control the less varying "trait like" properties, and to align them to homologous traits of stakeholder groups. This is analogous to the marketing of new quality attributes in business.

Consider now the mode of analysis. Efficiency stages would challenge analysts to utilize more formal methods, both because of their analytical strength and their impressiveness, particularly to laymen. Such methods may become institutionalized or legally mandated. Optimization methodologies should be common, especially cost minimization calculations. One would expect more comprehensive planning of activities. However, in principle, there should always remain kudos for simple, incremental actions that result in cost cuts. A consequence of all this would likely be that organization leaders carefully control and limit the internal coalition of the organization, to minimize the cost of side payments to coalition members and to avoid long-run commitments.

By comparison, the expectation in responsiveness stages is that leaders will, like top corporate executives, identify and prioritize stakeholders, carefully studying the demands of each. They would then guide organization efforts to satisfice the demands of all legitimate stakeholders, and to more than satisfice demands of currently salient stakeholders. There might be less concern about coalition control, with external elements (and their demands) actually co-opted into the organization. This would also probably entail new long-term commitments and force consideration of entirely new variables and measures.

\section{DISCUSSION}

What then do these things concerning quality imply for executive practices and ethical action? First and foremost that managers must be true to their salient stakeholders, especially their stockholders, customers, workers, and producers of complementary goods. Toward stockholders, the management imperative is to maximize the longrun stream of revenues, and with it stock price. At any juncture, this may be done, but is not necessarily done through producing the maximum quality output.

True long-run optimization involves finding an optimal set of quality levels which will typically have a monotonic upward trend. A consistent commitment to these levels is most desirable. Ideally, this commitment would be explicitly stated (or at least strongly connoted) in the organization's mission and vision statements. Advertising and intense lobbying to increase the weight, $w_{i}$, of an attribute(s) is fully permissible. Sound business and ethical practices then demand that a firm follow through to deliver the promised quality attributes at the stated levels. The customer trust engendered by reliable quality at the expected level is a strong, intangible business asset.

The firm's workforce, their internal stakeholders, must ultimately do the work to produce this consistent quality. It is therefore critical to explicitly communicate and repeat the firm's commitment to the desired quality level. Employee empowerment in the required actions is mandated. Further, management must incorporate enactment of quality explicitly and visibly into the system of incentives, as something consistently rewarded.

Special considerations, ethical as well as practical, should be given to the firms that produce complementary goods used in tandem with those of the focal firm. These firms are especially vulnerable to the focal firm's actions (Pierce, 2009), although this facet often draws scant attention in most business planning. The focal firm's overall perceived quality and actual market position usually depend on consistent maintenance of a set of complementarity $a_{i}$. It is therefore practically and ethically necessary to help suppliers of complementary goods avoid loss and continue their own interested commitments. This may be accomplished by consistent quality maintenance, negotiation of technical standards, and informal signaling.

Quality improvements are important changes. Managers and organizations, in both the public and private spheres, are judged largely on their adaptability to near constant change. Change management requires considerable 
organizational learning (Paton \& McCalman, 2008). However, learning the new requires unlearning of the old (Prahalad \& Bettis, 1995), and the possible learning during any time increment is a function of the unlearning that occurred in the previous increment, as defined in an "unlearning curve." In both spheres, quantification can abet the learning process through facilitating unlearning. This is because numbers represent quantities, and quantity itself is a quality, one that enables more precise description of what must be unlearned. Unlearning should, theoretically, proceed more rapidly in private enterprise, because of the clear objective function of profit, which provides a skeleton framework for quantitative description. The most severe unlearning would involve elimination of organization elements or departments, a process more easily accomplished in industry.

Shared meanings emerge when people interact in communication (Weick, 1969; Smircich \& Stubbart, 1985; Prahalad \& Bettis, 1986; Nebeker, 2003). Readily interpretable numbers facilitate shared meanings for those cognitive and physical activities by which people "socially construct" the environment about them (Berger \& Luckmann, 1967). Combining perceived and constructed views of reality, Weick (1969) suggests that individuals "enact" their environments by acting, perceiving and reacting to the results, and then adjusting. A desirable outcome of such social construction would be a corporate culture valuing quality production, with workers feeling empowered to act on continuous improvement norms.

\section{REFERENCES}

1. $\quad$ Andrews, K. R. (1971) The concept of corporate strategy. Homewood, Ill., Dow Jones-Irwin.

2. Berger, P. L. \& Luckmann, T. (1967) The social construction of reality: A treatise on the sociology of knowledge. Garden city, NY: Anchor

3. Boyd, B. K., Dess, G. G. \& Rasheed, A. M. A. (1993) Divergence between archival and perceptual measures of the environment: Causes and consequences. Academy of Management Review, 18: 204-226.

4. Butterfield, K. D., Trevino, L. K. \& Weaver, G. R. (2006) Moral Awareness in Business Organizations: Influences of Issue-related and Social Context Factors. Human Relations, 53: 981-1018.

5. Castrogiovanni, G. J. (1991) Environmental munificence: A theoretical assessment. Academy of Management Review, 16: 542-565.

6. $\quad$ Frederickson, H. G. (1997) The spirit of public administration. San Francisco: Jossey-Bass.

7. Gowdy, L. N. (2006) Logics Origin of Ethics, Morals, Virtue, and Quality. Amarillo, TX: Woven Strings Publishing.

8. Hax, C. H. \& Majluf, N. S. (1984) Strategic management: An integrated perspective. Englewood Cliffs, New Jersey: Prentice-Hall.

9. Heider, F. (1944) Social Perception and Phenomenal Causality. Psychological Review, 51: 358-74.

10. Herold, D. \& Greller, M. (1977) Feedback: The Definition of a Construct. Academy of Management Journal. 20: 142-147.

11. Hirschman, A. O. (1982) Shifting involvements: Private interests and public action. Princeton, New Jersey: Princeton University Press.

12. House, R. J. (1971) A Path-Goal theory of leader effectiveness. Administrative Science Quarterly, 16(92); 321-329.

13. Ilgen, D. R., Fisher, C.D. \& Taylor, M. S. (1979) Consequences of Individual Feedback on Behavior in Organizations. Journal of Applied Psychology, 64(4):349-371.

14. Jones, E. E. \& Davis, K. E. (1965) From Acts to Dispositions: The Attribution Process in Person Perception. In L. Berkowitz (ed.) Advances in experimental social psychology, vol. 2, New York: Academic Press.

15. Jones, T. M. (1991) Ethical Decision making by Individuals in Organizations: An issue- contingent model. Academy of Management Review, 16:366-395

16. Kaufman, H. (1985) Time, chance, and organization: National selection in a perilous environment. Chatham, New Jersey: Chatham House.

17. Kelley, H. H. (1967) Attribution Theory in Social Psychology, in D. Levine (ed.), Nebraska Symposium on Motivation, 15: 192-240, Nebraska: University of Nebraska Press.

18. Kepner, C. H. \& Tregoe, B. B. (1965) The rational manager. New York: McGraw-Hill.

19. Kerfoot, K. (2003) Attending to weak signals: the leader's challenge. Nursing Economics. Nov.-Dec.: 1-4.

20. Kozielecki, J. (1972) A Model for Diagnostic Problem Solving. Acta Psychologica, 36: 370-380. 
21. Kuhn, T. S. (1980) The structure of scientific revolutions. Chicago: U. Chicago Press.

22. Lampe, J. \& Finn, D. (1992) A Model of Auditors' ethical decision process. Auditing: A Journal of Practice and Theory. Supplement, 1-21.

23. Lerner, A.W. \& Wanat, J. (1983) Fuzziness and Bureaucracy. Public Administration Review.43, 500-510.

24. Liegey P. (2000) Hedonic quality adjustment methods. US: Bureau of Labor Statistics.

25. Lindblom, C. E. (1959) The science of "muddling through." Public Administrative Review, 19(2): 79-88.

26. Mankelwicz, J. M., Boseman, F. G. \& Milutinovich, J. S. (1987) Strategic Feedback: A Construct Definition, Proceedings. Pacific Conference, Decision Sciences Institute.

27. March, J. G. \& Simon, H. A. (1958) Organizations. New York: John Wiley

28. Mitchell, R. K., Agle, B. R. \& Wood, D. J. (1997) Toward a Theory of Stakeholder Salience: Defining the Principle of Who and What really counts. Academy of Management Review, 22: 853-886.

29. Nash, J. F. (1951) Noncooperative Games. Annals of Mathematics, 54: 286-295.

30. Nebeker, D. M. (1975) Situational favorability and perceived environmental uncertainty. Administrative Science Quarterly, 20: 281-294.

31. Paton, R. A. \& McCalman, J. (2008) Change management: A guide to effective implementation. $3^{\text {rd }}$ ed. Los Angeles: SAGE.

32. Pierce, L. (2009) Big Losses in Ecosystem Niches: How Core Firm Decisions Drive Complementary product shakeouts. Strategic Management Journal, 30: 323-347.

33. Pirsig, R. (1974) Zen and the art of motorcycle maintenance: An inquiry into values. New York: William Morrow and company.

34. Prahalad, C. K. \& Bettis, R. A. (1986) The dominant logic: A new linkage between diversity and performance. Strategic Management Journal, 7: 485-501.

35. Rest, J. R. (1986) Moral development: Advances in research and theory. New York: Praeger.

36. Reynolds, S. J. (2006) Moral Awareness and Ethical Predispositions: Investigating the Role of Individual Differences in the Recognition of Moral Issues. Journal of Applied Psychology, 91(1):233-243.

37. Rosen, S. (1974) Hedonic prices and implicit markets. Journal of Political Economy, 82:34-55.

38. Simon, H. A. (1945) Administrative Behavior. New York: Free Press.

39. Smircich, L. \& Stubbart, C. (1985) Strategic management in an enacted world. Academy of Management Review, 10: 724-736.

40. Triplett, J. (2006) Handbook on Hedonic Indexes and Quality Adjustments in Price Indexes. Organization for Economic Cooperation and Development.

41. Von Neumann, J. \& Morgenstern, O. (1944) The theory of games and economic behavior. Princeton, NJ: Princeton University Press.

42. Weick, K. E. (1969) The social psychology of organizing. Reading, MS: Addison-Wesley.

43. Zadeh, L. A. 1965. Fuzzy Sets. Information and Control, 8: 338-353 
NOTES 